\title{
CARACTERIZACÃO MOLECULAR DE ACESSOS DE MANDIOCA AÇUCARADOS E NÃO AÇUCARADOS
}

\author{
Molecular characterization of sugary and non-sugary cassava accessions \\ Eduardo Alano Vieira ${ }^{1}$, Josefino de Freitas Fialho ${ }^{2}$, Fábio Gelape Faleiro ${ }^{2}$, \\ Graciele Bellon $^{2}$, Kenia Gracielle da Fonceca ${ }^{2}$, Luiz Joaquim Castelo Branco Carvalho ${ }^{3}$
}

\begin{abstract}
RESUMO
Acessos de mandioca que armazenam açúcares livres em suas raízes de reserva e não somente amido, como os acessos de mandioca cultivados comercialmente, vêm recebendo destaque atualmente. Esses acessos são popularmente conhecidos como mandiocas açucaradas ou mandiocabas, e evidenciam potencial de uso na produção de álcool combustível. Entretanto, esse germoplasma ainda não foi suficientemente estudado quanto àsua variabilidade genotípica, o que é fundamental para sua conservação e utilização no melhoramento genético. Neste tabalho, objetivou-se caracterizar por meio de marcadores RAPD 14 acessos de mandioca açucarados e não açucarados. Em laboratório, os acessos foram avaliados por meio de 12 iniciadores RAPD. Posteriormente, foi estimada a matriz de dissimilaridade genética entre os acessos, por meio da utilização do complemento do índice de Jaccard. Os iniciadores geraram 131 marcadores RAPD, dos quais $73 \%$ foram polimórficos, evidenciando a existência de variabilidade e a eficiência da técnica de RAPD. Os acessos mais similares foram BGMC 1207 e BGMC 1209, ambos açucarados e os menos similares foram o açucarado BGMC 1219 e a cultivar BGMC 436. Os acessos foram divididos em quatro grupos, sendo o primeiro grupo formado pelos 10 acessos açucarados, o segundo grupo formado por dois acessos locais não açucarados, o terceiro e o quarto foram formados pelos acessos melhorados BGMC 753 e BGMC 436. Os resultados obtidos revelaram a existência de elevada variabilidade genética entre os acessos avaliados e diferenciaram os acessos açucarados das cultivares locais não açucaradas e das cultivares comerciais não açucaradas.
\end{abstract}

Termos para indexação: Manihot esculenta Crantz, recursos genéticos, melhoramento genético, variabilidade genética.

\section{ABSTRACT}

Emphasis has been given lately to cassava accessions that accumulate free sugars in their storage roots, besides starch, such as the commercial cultivars. These accessions are popularly known as sugary cassavas or "mandiocabas", and present a high potential for the use in ethanol biofuel production. Nevertheless, this germplasm was not yet sufficiently studied regarding its genotypic variability, which is of fundamental importance for its conservation and use in genetic improvement. The objective of this work was to characterize, via RAPD marker, 14 sugary and non-sugary cassava accessions. Within Laboratory conditions, the accessions were evaluated by using 12 RAPD primers. Afterwards, the matrix of genetic dissimilarity among the acessions was estimated by using the complement of Jaccard index. The primer generated 131 RAPD markers, among which $73 \%$ were polymorphic, highlightening the existence of genetic variability and efficiency of the RAPD technique. The most similar accessions were BGMC 1207 and BGMC 1209, both sugary ones, and the least similar, the sugary accession BGMC 1219 and the cultivar BGMC 436 . The accessions were divided into four groups, the first group was composed by the 10 sugary accessions, the second group consistecs of two local nonsugary accessions, the third and fourth groups were composed by the improved accessions BGMC 753 and BGMC 436. The results obtained reveal the existence of high genetic variability among the evaluated accessions and differed the sugary accessions from local non-sugary and the non-sugary commercial cultivars.

Index terms: Manihot esculenta Crantz, genetic resources, genetic improvement, genetic variability.

(Recebido em 11 de junho de 2009 e aprovado em 21 de maio de 2010)

\section{INTRODUÇÃO}

As raízes tuberosas da mandioca (Manihot esculenta Crantz) figuram entre as mais importantes fontes de calorias na alimentação da população de vários países tropicais, em especial na África e no Brasil (Cock, 1985). A cultura tem destaque especialmente em países em desenvolvimento, principalmente em razão da sua rusticidade e da capacidade de produzir elevadas quantidades de amido em condições em que outras culturas sequer sobreviveriam. No Brasil, centro de origem e diversidade da espécie (Olsen, 2004) a mandioca é cultivada em todas as regiões, visando a sua utilização na indústria, alimentação humana e animal (Oliveira \& Moraes, 2009; Lopes et al., 2010).

Atualmente, vêm recebendo amplo destaque entre pesquisadores e produtores de mandioca do Brasil e do

\footnotetext{
Empresa Brasileira de Pesquisa Agropecuária/Embrapa Cerrados - BR 020 - km 18 - 73310-970 - Planaltina, DF - vieiraea@cpac.embrapa.br ${ }^{2}$ Empresa Brasileira de Pesquisa Agropecuária/Embrapa Cerrados - Planaltina, DF

${ }^{3}$ Empresa Brasileira de Pesquisa Agropecuária/Embrapa Cenargem - Brasília, DF
} 
mundo, acessos de mandioca popularmente conhecidos como mandiocas açucaradas ou mandiocabas, que armazenam açúcares livres em suas raízes de reserva e não somente amido, como a grande maioria dos acessos de mandioca cultivados comercialmente (Carvalho et al., 2000, 2004). Assim, a mandioca que sempre foi cultivada em razão de suas raízes tuberosas ricas em amido e/ou de sua parte aérea rica em proteínas, apresenta agora novas possibilidades de utilização na indústria. Esses acessos diferenciados podem vir a ser empregados na produção de glicose sem hidrólise do amido, na produção de amido com variabilidade na proporção amilose/amilopectina, na produção de amido do tipo glicogênio, na produção de álcool (combustível e para indústria de cosméticos), na siderúrgia, entre outras utilidades (Carvalho et al., 2000, 2004).

Entretanto, esses acessos ainda não foram suficientemente estudados quanto à sua variabilidade genética, o que é fundamental para sua conservação e utilização direta ou no melhoramento genético. Estudos de variabilidade genética possibilitam inferências a respeito da organização do germoplasma, aumentam a eficiência da amostragem de genótipos, auxiliam na definição de combinações de genitores, na incorporação de genes de germoplasma exótico e na recomendação de cultivares para determinada região, quando o objetivo é aumentar a base genética sob cultivo (Mohammadi \& Prasana, 2003).

A utilização isolada ou em conjunto de dados fenotípicos e moleculares são as principais ferramentas para a estimativa da variabilidade genética entre um conjunto de genótipos (Vieira et al., 2007). Em mandioca, os marcadores moleculares vêm sendo utilizados com elevada frequência na estimativa da variabilidade genética dentro da espécie Manihot esculenta Crantz (Assante \& Offei, 2003; Costa et al., 2003; Zacarias et al., 2004; Ferreira et al., 2008) ou entre diferentes espécies do gênero Manihot (Colombo et al., 2000; Carvalho \& Schaal, 2001; Olsen, 2004), uma vez que estes apresentam ampla capacidade de acessar as informações contidas no genoma de um organismo. Em mandioca, também vêm sendo utilizados caracteres fenotípicos em associação com as técnicas multivariadas, na quantificação da variabilidade genética em mandioca (Mkumbira et al., 2003; Nick et al., 2008). Em relação aos caracteres fenotípicos, os marcadores moleculares apresentam a vantagem de não sofrerem influência do ambiente e de exibirem grande capacidade de detecção de variabilidade genética, porém apresentam a desvantagem de acessarem o genoma como um todo e não somente as regiões responsáveis pela manifestação dos caracteres de interesse. Dentre as diversas técnicas de marcadores moleculares, o RAPD (polimorfismo de DNA amplificado ao acaso) merece destaque, pelo baixo custo, pela rápida e fácil execução e pelo fato de não exigir a síntese de iniciadores específicos.

Neste trabalho, objetivou-se caracterizar por meio de marcadores RAPD 14 acessos de mandioca açucarados e não açucarados conservados no Banco Regional de Germoplasma de Mandioca do Cerrado (BGMC).

\section{MATERIAL E MÉTODOS}

Foram utilizados 14 acessos de mandioca mantidos no Banco Regional de Germoplasma de Mandioca do Cerrado (BGMC), sendo 10 acessos açucarados, dois acessos locais introduzidos no BGMC como sendo açucarados e duas cultivares recomendadas para o cultivo na região do Cerrado, sendo uma de mesa e uma de indústria (Tabela 1).

As amostras de DNA utilizadas na obtenção de marcadores RAPD foram extraídas a partir de folhas em estágio intermediário de maturação, por meio do método do CTAB, com modificações (Faleiro et al., 2003). As reações de amplificação foram realizadas em um volume total de $13 \mu \mathrm{L}$, contendo Tris- $\mathrm{HCl} 10 \mathrm{mM}$ (pH 8,3), $\mathrm{KCl} 50$ $\mathrm{mM}, \mathrm{MgCl} 23 \mathrm{mM}, 100 \mu \mathrm{M}$ de cada um dos desoxiribonucleotídios (dATP, dTTP, dGTP e dCTP), $0,4 \mu \mathrm{M}$ de um iniciador (Operon Technologies Inc., Alameda, CA, EUA), uma unidade da enzima Taq polimerase e, aproximadamente, $15 \mathrm{ng}$ de DNA. Para obtenção dos marcadores RAPD, foram utilizados 12 iniciadores decâmeros: OPD $(02,08,18), \mathrm{OPF}(08), \mathrm{OPG}(05,08,09,15$ e 16), OPH (10, 16 e 17). Na etapa de amplificação dos segmentos de DNA, foi utilizado um termociclador programado para 40 ciclos, cada um constituído pela seguinte sequência: 15 segundos a $94^{\circ} \mathrm{C}, 30$ segundos a $35^{\circ} \mathrm{C}$ e 90 segundos a $72^{\circ} \mathrm{C}$. Após os 40 ciclos, foi realizada uma etapa de extensão final de seis minutos a $72^{\circ} \mathrm{C}$, e posteriormente, a temperatura foi reduzida para $4^{\circ} \mathrm{C}$. Após a amplificação, foram adicionadas, a cada amostra, $3 \mu \mathrm{lde}$ uma mistura de azul de bromofenol $(0,25 \%)$ e glicerol $(60 \%)$ em água. Essas amostras foram aplicadas em gel de agarose $(1,2 \%)$, corado com brometo de etídio, submerso em tampão TBE (Tris-Borato $90 \mathrm{mM}$, EDTA 1 $\mathrm{mM})$. A separação eletroforética foi de, aproximadamente, quatro horas, a 90 volts. Ao término da corrida, os géis foram fotografados sob luz ultravioleta.

Os produtos das reações de amplificação (marcadores RAPD) foram classificados em presença (1) e ausência (0) de bandas e convertidos em uma matriz de dados binários, a partir da qual foi estimado: i) o conteudo 
de informação de polimorfismo (CIP) de cada marcador de cada iniciador, por meio da fórmula $C I P=2 \mathrm{f}_{\mathrm{i}}\left(1-\mathrm{f}_{\mathrm{i}}\right)$, na qual fi é a frequência de presença de banda (1), e (1-fi) é a frequência de ausência de banda (0) e, posteriormente, foi estimado o CIP médio de que cada iniciador por meio da média aritmética do CIPs obtidos; ii) o índice do marcador (IM) calculado para cada iniciador por meio da fórmula IM = PIC x nbp, onde npb é o número de bandas polimórficas (Powell et al., 1996); e iii) a similaridade genética entre os acessos, por meio do coeficiente de Jaccard (Jaccard, 1908), conforme a equação: $\mathrm{S}_{\mathrm{ij}}=\mathrm{N}_{\mathrm{ij}} /$ $\left(\mathrm{N}_{\mathrm{ij}}+\mathrm{N}_{\mathrm{i}}+\mathrm{N}_{\mathrm{j}}\right)$; em que: $\mathrm{N}_{\mathrm{ij}}=$ número de bandas presentes em ambos os acessos $\mathrm{i}$ e $\mathrm{j} ; \mathrm{N}_{\mathrm{i}}=$ número de bandas presentes no acesso $\mathrm{i}$, e $\mathrm{N}_{\mathrm{j}}=$ número de bandas presentes no acesso j. A similaridade genética foi transformada em dissimilaridade genética segundo a equação: $\mathrm{D}_{\mathrm{ij}}=1-\mathrm{S}_{\mathrm{ij}}$, em que: $D_{\mathrm{ij}}=$ dissimilaridade genética entre cada par de $\mathrm{i}$ e $\mathrm{j}$ acessos; $\mathrm{S}_{\mathrm{ij}}=$ similaridade genética entre cada par de $\mathrm{i}$ $\mathrm{e} \mathrm{j}$ acessos.

Com base na matriz de dissimilaridade, foi construído um dendrograma, por meio do método de agrupamento da distância média (UPGMA). O ajuste entre a matriz de dissimilaridade e o dendrograma foi estimado pelo coeficiente de correlação cofenética (r), conforme Sokal \& Rohlf (1962), por meio do programa computacional NTSYS pc 2.1 (Rohlf, 2000). A estabilidade dos agrupamentos foi computada por meio da análise de Bootstraping com 500 replicações por meio do programa Genes (Cruz, 2001).

\section{RESULTADOS E DISCUSSÃO}

Os 12 iniciadores utilizados geraram um total de 131 marcadores RAPD, dos quais 96 (73\%) foram polimórficos, evidenciando a existência de variabilidade genética e a eficiência da técnica de RAPD na detecção da variabilidade genética presente nos 14 acessos estudados. A elevada variabilidade genética dos acessos observada com base em marcadores moleculares é explicada pela dimensão continental do Brasil e da grande diversidade ambiental (solo e clima) e cultural (diferentes usos da mandioca) com a qual a mandioca evoluiu. A alta variabilidade genética de acessos de mandioca e a eficiência da técnica de RAPD na detecção de tal variabilidade têm sido verificada em vários trabalhos (Colombo et al., 2000; Asante \& Offei, 2003; Costa et al., 2003; Zacarias et al., 2004; Ferreira et al., 2008).

Dentre os iniciadores utilizados, o que evidenciou o maior número de bandas polimórficas (12), maior conteúdo de informação de polimorfismo (CIP) $(0,27)$ e maior informação de polimorfismo (MI) $(2,70)$ foi o iniciador OPG08 (Tabela 2). O menor número de bandas polimórficas (3) e CIP $(0,07)$ foi revelado pelo iniciador OPH-10, enquanto que o menor MI $(0,51)$ foi revelado pelo marcador OPH-10 (Tabela 2). Em meio às bandas polimórficas, duas foram detectadas em todos os acessos não açucarados e em nenhum açucarado (nos iniciadores OPH-10 e OPH-17), enquanto que uma banda foi detectada em todos os acessos açucarados e em nenhum dos não açucarados

Tabela 1 - Acessos de mandioca açucarados e não açucarados analisados e seus respectivos nomes comuns.

\begin{tabular}{lll}
\hline Acessos & Nome comum & Tipo \\
\hline BGMC 1208 & Sem denominação & local não açucarado \\
BGMC 1210 & Sem denominação & local não açucarado \\
BGMC 1212 & Sem denominação & açucarado \\
BGMC 1213 & Sem denominação & açucarado \\
BGMC 1211 & Sem denominação & açucarado \\
BGMC 1217 & Iguaçu & açucarado \\
BGMC 1215 & Castanhal & açucarado \\
BGMC 1207 & Sem denominação & açucarado \\
BGMC 1209 & Sem denominação & açucarado \\
BGMC 1214 & Sem denominação & açucarado \\
BGMC 1219 & São Francisco 1 & açucarado \\
BGMC 1220 & São Francisco 2 & açucarado \\
BGMC 753 & IAC 756-70 (mandioca de mesa) & melhorado não açucarado \\
BGMC 436 & IAC 12 (mandioca de indústria) & melhorado não açucarado \\
\hline
\end{tabular}


(no iniciador OPF-8). Essas bandas podem constituir marcadores com grande potencial para a diferenciação dos genótipos quanto à presença ou ausência do fenótipo açucarado nas raízes. Além disso, podem vir a ser importantes no mapeamento genético, para a detecção de associação entre marcadores e locos controladores do caráter (Okogbenin et al., 2006), uma vez que podem estar pelo menos parcialmente associadas ao fenótipo raízes açucaradas.

A dissimilaridade genética estimada por meio de marcadores RAPD evidenciou que os acessos mais similares foram BGMC 1207 e BGMC 1209, ambos açucarados e que os menos similares foram o acesso açucarado BGMC 1219 e a cultivar de mandioca de indústria recomendada para o plantio na região do cerrado BGMC 436. A análise da Figura 1 e os valores percentuais de agrupamentos coincidentes após 500 ciclos de bootstraping permitiram a partição dos acessos avaliados em quatro grupos de similaridade. $\mathrm{O}$ primeiro grupo formado pelos 10 acessos açucarados (BGMC 1212, BGMC 1213, BGMC 1211, BGMC 1217, BGMC 1215, BGMC 1207, BGMC 1209, BGMC 1214, BGMC 1219 e BGMC 1220) com uma percentagem de agrupamentos coincidentes de $96 \%$. O segundo grupo formado pelos acessos locais BGMC 1208 e BGMC 1210, que foram introduzidos no BGMC como açucarados, mas que não evidenciaram o fenótipo nas condições do Cerrado, possivelmente em razão de falhas ocorridas na etiquetagem destes acessos durante a coleta dos mesmos com uma percentagem de agrupamento coincidente de $100 \%$. O terceiro e o quarto grupo de similaridade foram representados pelo acesso BGMC 753 (cultivar recomendada para a mesa) e pelo acesso BGMC 436 (cultivar recomendada para a indústria), respectivamente. $\mathrm{O}$ não agrupamento das cultivares para mesa e indústria evidencia as diferenças genéticas entre elas e também em relação aos acessos açucarados.

Os resultados revelaram a existência de variabilidade genética entre os acessos açucarados avaliados, já que não foi detectada nenhuma similaridade de $100 \%$, o que é importante para o melhoramento genético que é dependente de variabilidade (Allard, 1999). Essa variabilidade em nível de DNA aponta para a possibilidade de também haver variação quanto ao potencial agronômico no grupo de acessos açucarados mantidos no BGMC. A técnica de RAPD também se mostrou eficiente na discriminação dos acessos em função do fenótipo açúcares nas raízes, uma vez que nenhum acesso não açucarado agrupou-se com acessos açucarados no primeiro nível hierárquico, o que, provavelmente, seja reflexo desses acessos terem uma origem e domesticação diferenciada. Esse resultado é interessante uma vez que muitos estudos têm revelado a inexistência de associação entre o local geográfico de coleta de acessos de mandioca e as distâncias genéticas estimadas por meio de marcadores moleculares (Mühlen et al., 2000; Assante \& Offei, 2003; Costa et al., 2003; Zacarias et al., 2004; Ferreira et al., 2008). Entretanto,

Tabela 2 - Iniciadores utilizados para obtenção dos marcadores RAPD, respectivo número de bandas polimórficas, número de bandas monomórficas, conteudo de informação de polimorfismo (CIP) e indíce do marcador (IM).

\begin{tabular}{lccccc}
\hline Iniciadores & Sequência $5^{\prime} \rightarrow 3^{\prime}$ & $\mathbf{N}^{\mathbf{0}}$ de bandas polimórficas & $\mathbf{N}^{\circ}$ de bandas monomórficas & CIP & IM \\
\hline OPD-02 & GGACCCAACC & 5 & 0 & 0,17 & 0,85 \\
OPD-08 & GTGTGCCCCA & 9 & 4 & 0,18 & 1,62 \\
OPD-18 & GAGAGCCAAC & 9 & 9 & 0,07 & 0,63 \\
OPF-08 & GGGATATCGG & 11 & 2 & 0,23 & 2,53 \\
OPG-05 & CTGAGACGGA & 10 & 4 & 0,19 & 1,90 \\
OPG-08 & TCACGTCCAC & 12 & 0 & 0,20 & 2,40 \\
OPG-09 & CTGACGTCAC & 9 & 1 & 0,19 & 1,71 \\
OPG-15 & ACTGGGACTC & 5 & 2 & 0,24 & 1,20 \\
OPG-16 & AGCGTCCTCC & 5 & 4 & 0,15 & 0,75 \\
OPH-10 & CCTACGTCAG & 3 & 3 & 0,17 & 0,51 \\
OPH-16 & TCTCAGCTGG & 10 & 3 & 0,27 & 2,70 \\
OPH-17 & CACTCTCCTC & 8 & 3 & 0,20 & 1,60 \\
\hline TOTAL & & 96 & 35 & 0,19 & 1,53 \\
\hline
\end{tabular}

Ciênc. agrotec., Lavras, v. 35, n. 3, p. 455-461, maio/jun., 2011 
Colombo et al. (2000) detectaram a existência de tendência de agrupamentos coincidentes quando foram consideradas características como precipitação e temperatura do local origem dos acessos. O coeficiente de correlação cofenética do dendrograma $(r=0,99)$ revelou elevado ajuste entre a representação gráfica da dissimilaridade genética e a matriz de dissimilaridade original, o que justifica que sejam realizadas inferências por meio da avaliação visual da Figura 1.

Fato interessante foi que os acessos BGMC 1208 e BGMC 1210 que haviam sido introduzidos no BGMC como açucarados e que somente após a coleta de amostras foliares para a execução deste estudo foi detectado que nas condições do Cerrado brasileiro não apresentam fenótipo açucarado formaram um grupo isolado em todas as técnicas empregadas. Isso revela que esses acessos apresentam um backgroud genético diferente dos acessos açucarados e das variedades recomendas para o cultivo na região do Cerrado. $\mathrm{O}$ fato dos dois acessos oriundos de programas de melhoramento genético do Instituto Agronômico de Campinas (IAC) BGMC 753 e BGMC 436 terem evidenciado elevada divergência genética em relação aos demais acessos analisados (açucarados e genótipos locais não açucarados) revelou que o processo de seleção artificial realizado pelos melhoristas nas estações de pesquisa redundou em ampla divergência genética entre os acessos melhorados e os acessos locais açucarados ou não açucarados (Figura 1). Resultados semelhantes haviam sido reportados por Assante \& Offei (2003) ao estudarem a variabilidade genética de 47 acessos locais de mandioca e de três cultivares.

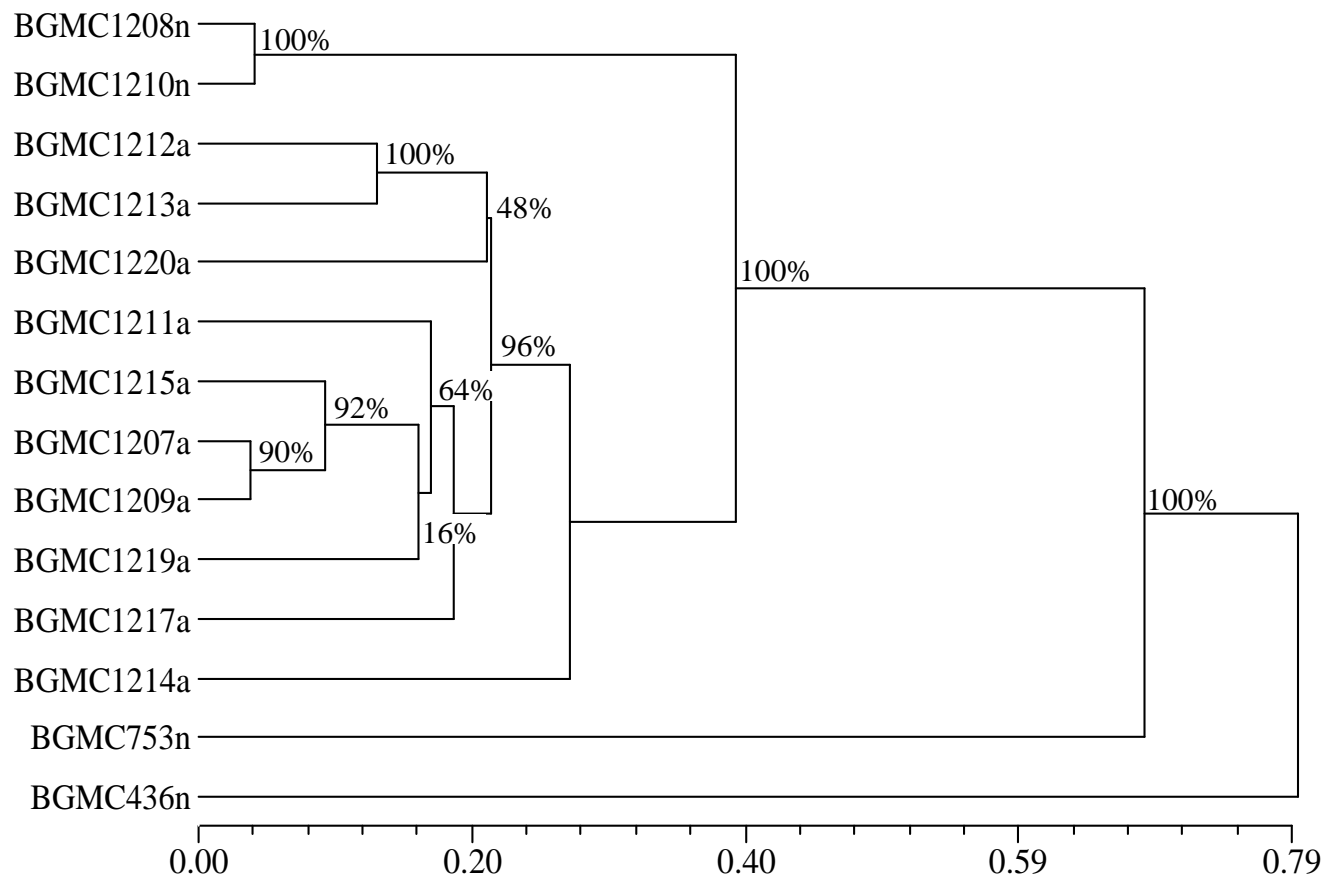

Figura 1 - Dendrograma resultante da análise de agrupamento de 10 acessos de mandioca açucarados (a) e 4 não açucarados (n), obtido pelo método UPGMA, utilizando o complemento do índice de similaridade de Jaccard, obtido a partir da análise de RAPD, como medida de distância genética. Os valores encontrados nos grupos indicam o valor percentual de vezes que os genótipos agruparam juntos em 500 ciclos de análise de bootstraping. O valor do coeficiente de correlação cofenética (r) é de 0,99 . 


\section{CONCLUSÕES}

Os marcadores RAPD mostraram eficiência na determinação da variabilidade genética entre acessos de mandioca açucarados e não açucarados e diferenciaram claramente os acessos açucarados dos acessos locais não açucarados e dos acessos melhorados.

\section{AGRADECIMENTOS}

Os autores agradecem à Embrapa, Fundação Banco do Brasil, CNPq e ao Programa Biodiversidade Brasil x Itália pelos auxílios financeiros recebidos.

\section{REFERÊNCIAS BIBLIOGRÁFICAS}

ALLARD, R.W. Principies of plant breeding. 2.ed. New York: J.Wiley, 1999. 254p.

ASANTE, I.K.; OFFEI, S.K. RAPD-based genetic diversity study of fifty cassava (Manihot esculenta Crantz) genotypes. Euphytica, Wageningen, v.131, n.1, p.113-119, 2003.

CARVALHO, L.J.C.B.; CABRAL, G.B.; CAMPOS, L. Raiz de reserva de mandioca: um sistema biológico de múltipla utilidade. Brasília: CENARGEN, 2000. 16p.

CARVALHO, L.J.C.B.; SCHAAL, B.A. Assessing genetic diversity in the cassava (Manihot esculenta Crantz) germplasm collection in Brazil using PCR-based markers. Euphytica, Wageningen, v.120, n.1, p.130-140, 2001.

CARVALHO, L.J.C.B.; SOUZA, C.R.B.; CASCARDO, J.C.M.; CAMPOS, L. Identification and characterization of novel cassava (Manihot esculenta Crantz) clone with high free sugar content and novel starch. Plant Molecular Biology, Dordrecht, v.56, n.4, p.643-659, 2004.

COCK, J. Cassava: new potential for a neglected crop. Boulder: Westview, 1985. 240p.

COLOMBO, C.; SECOND, G.; CHARRIER, A. Diversity within American cassava germ plasm based on RAPD markers. Genetics and Molecular Biology, Ribeirão Preto, v.23, n.1, p.189-199, 2000.

COSTA, M.R.; CARDOSO, E.R.; OHAZE, M.M.M. Similaridade genética de cultivares de mandioca (Manihot esculenta) por meio de marcadores RAPD. Ciência e Agrotecnologia, Lavras, v.27, n.1, p.158-164, 2003.
CRUZ, C.D. Programa genes: aplicativo computacional em genética e estatística. Viçosa, MG: UFV, 2001. 648p.

FALEIRO, F.G.; FALEIRO, A.S.G.; CORDEIRO, M.C.R.; KARIA, C.T. Metodologia para operacionalizar a extração de DNA de espécies nativas do cerrado. Planaltina: CPAC, 2003. 6p.

FERREIRA, C.F.; ALVES, E.; PESTANA, K.N.; JUNGHANS, D.T.; KOBAYASHI, A.K.; SANTOS, V.J.; SILVA, R.P.; SILVA, P.H.; SOARES, E.; KUKUDA, W. Molecular characterization of cassava (Manihot esculenta Crantz) with yellow-orange roots for betacarotene improvement. Crop Breeding and Applied Genetics, Viçosa, v.8, n.1, p.23-29, 2008.

JACCARD, P. Nouvelles recherches sur la distribution florale. Bulletin Société Vaudoise des Sciences Naturelles, v.44, n.2, p.223-270, 1908.

LOPES, A.C.; VIANA, A.E.S.; MATSOMOTO, S.N.; CARDOSO JÚNIOR, N. dos S.;SÃO JOSÉ, A.R. Complementação da irrigação e épocas de colheita de mandioca cv.coqueiro no Planalto de Conquista, BA.

Ciência e Agrotecnologia, Lavras, v.34,n.3, p.579-587, maio/jun., 2010.

\section{MKUMBIRA, J.; CHIWONA-KARLTUN, L.;} LAGERCRANTZ, U.; MAHUNGU, N.M.; SAKA, J.; MHONE, A.; BOKANGA, M.; BRIMER, L.; GULLBERG, U.; ROSLING, H. Classification of cassava into "bitter" and "cool" in Malawi: from farmer's perception to characterization by molecular markers. Euphytica, Wageningen, v.132, n.1, p.7-22, 2003.

MOHAMMADI, S.A.; PRASANNA, B.M. Analysis of genetic diversity in crop plants-Salient statistical tools and considerations. Crop Science, Madison, v.43, n.4, p.1235-1248, 2003.

MÜHLEN, G.S.; MARTINS, P.S.; ANDO, A. Variabilidade genética de etnovariedades de mandioca, avaliada por marcadores de DNA. Scientia Agricola, Piracicaba, v.57, n.2, p.319-328, 2000

NICK, C.; CARVALHO, M.; ASSIS, L.H.B.;

CARVALHO, S.P. Genetic dissimilarity in cassava clones determined by multivariate techniques. Crop Breeding and Applied Genetics, Viçosa, v.8, n.2, p.104110,2008 
OKOGBENIN, E.; MARIN, J.; FREGENE, M. An SSRbased molecular genetic map of cassava. Euphytica, Wageningen, v.147, n.3, p.433-440, 2006.

OLIVEIRA, M.A. de; MORAES, P.S.B. de. Características físico-químicas,cozimento e produtividade de mandioca cultivar IAC 576-70 em diferentes épocas decolheita. Ciência e Agrotecnologia, Lavras, v.33, n.3, p.837-843, maio/jun., 2009.

OLSEN, K.M. SNPs, SSRs and inferences on cassava's origin. Plant Molecular Biology, Dordrecht, v.56, n.4, p.517-526, 2004.

POWELL, W.; MORGANTE. M.; ANDRE, C.; HANAFEY, M.; VOGEL, J.; TINGEY, S.; RAFALSKI, A. The comparison of RFLP, RAPD, AFLP and SSR (microsatellite) markers for germplasm analysis. Molecular Breeding, Wageningen, v.2, n. 3, p.225-238, 1996.
ROHLF, F.J. NTSYS-pc: numerical taxonomy and multivariate analysis system. Version 2.1. New York: Exeter Software, 2000. 98p.

SOKAL, R.R.; ROHLF, F.J. The comparison of dendrograms by objective methods. Taxon, v.11, n.1, p.30-40, 1962.

VIEIRA, E.A.; CARVALHO, F.I.F.; BERTAN, I.; KOPP, M.M.; ZIMMER, P.D.; BENIN, G.; SILVA, J.A.G.; HARTWIG, I.; MALONE, G.; OLIVEIRA, A.C. Association between genetic distances in wheat (Triticum aestivum) as estimated by AFLP and morphological markers. Genetics and Molecular Biology, Ribeirão Preto, v.30, n.2, p.392-399, 2007.

ZACARIAS, A.M.; BOTHA, A.M.; LABUSCHAGNE, M.T.; BENESI, I.R.M. Characterization and genetic distance analysis of cassava (Manihot esculenta Crantz) germplasm form Mozambique using RAPD fingerprinting. Euphytica, Wageningen, v.138, n.1, p.49-53, 2004. 